\title{
Deliciously Exotic? Immigrant Grocery Shops and Their Non-Migrant Clientele
}

DOI 10.1515/irsr-2016-0004

Received: March 7, 2016; Accepted: April 29, 2016

Abstract: This paper examines native consumption practices in immigrant grocery stores. Drawing on qualitative research on immigrant food retail in Vienna, we reveal how native Austrians use immigrant grocery shops, how they purchase products and which meanings they attribute to the act of shopping. We identified two different modes of shopping: While consuming for convenience is driven by aspects of practicability, consuming for exceptionality is related to the attraction of 'the foreign'. This typology corresponds with two special types of consumers: The 'Because'-consumers use immigrant shops mainly because of the ethnicity associated with the shops, the owners and their staff. The 'Nevertheless'-consumers use these shops in spite of the entrepreneurs' (imagined) ethnic origin and their migrant background. While 'Because'-consumers run the risk of reproducing ethnic stereotypes, the 'Nevertheless'consumers may tend to retain or even strengthen their xenophobic resentments. These results partly challenge previous findings which argue that natives' shopping routines in immigrant stores have become increasingly ordinary. We conclude by suggesting further research to examine the conditions under which an everyday engagement with foreign culture is promoted - without falling into the trap of reproducing symbolic boundaries between the majority and the minority.

Keywords: consumption practices, non-migrant consumers, immigrant grocery shops, ethnicity, symbolic boundaries, integration

\footnotetext{
*Corresponding author: Michael Parzer Department of Sociology, University of Vienna, Rooseveltplatz 2, 1090 Vienna, E-mail: michael.parzer@univie.ac.at

Franz Astleithner, Irene Rieder, Department of Sociology, University of Vienna, Rooseveltplatz 2, 1090 Vienna
}

\section{Introduction}

Immigrant economies have become increasingly important and prevalent in many European cities. For instance, in Vienna, more than thirty per cent of all entrepreneurs have a migrant background (Schmatz and Wetzl, 2014). In Berlin, Hamburg, Zurich and Amsterdam similar findings can be reported (Rath and Eurofound, 2011). Many of these entrepreneurs work in food retail, including supermarkets, grocery shops, delis or bakeries. A vast majority of these shops offer products which are considered to be typical of their country of origin, ranging from 'Indian' spices to 'Turkish' pita or 'Polish' pierogi.

Previous research on immigrant economies mainly focused on their role for co-ethnics. Waldinger et al. (1990), for instance, emphasise that immigrant businesses provide goods and services for co-ethnics, whose needs could not be filled by entrepreneurs from the majority population. Moreover, consuming familiar products would serve immigrants as a resource for constructing (ethnic) identity and as a means to the preservation of specific traditions of the country of origin (Halter, 2000; Wang and Lo, 2007; Kraieski de Assunção, 2012). In political and public discourse, these observations are judged ambivalently. On the one hand, they have led to the use of pejorative connoted terms like 'ghetto'. Immigrant grocery shops - and generally immigrant economies - are considered as ethnic enclaves hindering integration through self-segregation. On the other hand, they are celebrated as important contributions to the local economy, offering pathways for the migrants' social mobility (Zhou, 2007; Leicht and Langhauser, 2014).

However, such a view overlooks the fact that many natives use immigrant businesses as well. Many entrepreneurs have 'broken out' of their ethnic enclave by addressing customers beyond their own community (Rusinovic, 2008; Parzer and Czingon, 2013). Furthermore, an increasing interest in ethnic products by members of the majority population can be observed (Everts, 2008; Stock, 2013; Yildiz, 2013). Strolling along 'multicultural' markets, buying 'exotic' delicacies in Asian or Indian 
gourmet food stores or buying pita at the 'Turkish' corner shop are practices that have become increasingly popular among well-educated urban residents and tourists in many European countries.

However, we know only very little about these practices. How do natives consume in immigrant grocery stores? Which products do they purchase and how do they attribute meaning to them? Which role does ethnic classification play in the customers' daily shopping routines?

In order to fill these research gaps, we examined native customers in immigrant grocery stores in Vienna. Drawing on our results, the aim of this paper is twofold: First, we give an overview on immigrant grocery stores and illustrate their main characteristics, particularly regarding the entrepreneurs' emphasis or downplaying of ethnic markers. Second, we reveal how native customers consume and attribute meaning to the shops, the owners and the offered products. Therefore, we use a broad definition of consumption, including not only the act of shopping, but also the use and the appropriation of the purchased products (Campbell, 1995: 102). By drawing on the concept of consumption practice (Warde, 2005), we do not limit our research to individual shopping behaviour, but focus on the routines, habitual practices and discourses associated with the act of shopping in immigrant grocery stores. In this context, we take a closer look at the classifications and categorisations of immigrant shops made by native consumers. When we speak of classifications, we refer to the concept of Jenkins (1994) who pointed out the interdependencies between external and internal classification and how these processes are embedded within power relations. Therefore, we want to reveal the effects of these classifications on symbolic boundaries (Wimmer, 2013).

Methodologically, we combined various different methods including participant observation in and in front of the shops, interviews with the entrepreneurs and/ or their employees as well as in-depth interviews and go-alongs with native customers. Accompanying people in grocery stores enabled us to examine consumption practices including the meanings associated with the offered and purchased products.

In the next section, we give a summary of recent literature on native consumption in immigrant shops. Then, in the following section, we describe the methods used in our qualitative research. After highlighting some of the characteristics of immigrant food retail in Vienna, we depict two modes of shopping in more detail: shopping for convenience and shopping for exceptionality. Finally, we conclude with some suggestions for further research.

\section{Immigrant entrepreneurs' native customers}

One of the most striking issues in immigrant business research is the ambivalent assessment of immigrant entrepreneurs as intermediaries between the majority population and minorities (Bonacich, 1973; Min, 1996; Dhingra, 2012). Non-migrant customers have gained some attention when scholars examined the various forms of interethnic interaction within immigrant economies and how these have an impact on social cohesion and integration processes. In his ethnographic study of immigrant grocery stores in the city of Stuttgart, Everts (2008) shows how consumption practices of natives may lead to everyday interactions between natives and immigrants and contribute to dissolving or blurring ethnic boundaries. Looking at local shopping streets in different cities, Kasinitz et al. (2016) have highlighted the role of immigrant businesses as they contribute to creating spaces of everyday diversity:

\begin{abstract}
In a world of perpetual journeys and migrations, they are often the first meeting place between people from different parts of the globe who are brought together by rituals of commerce rather than by shared cultural rituals. At their best, the superdiversity of many local shopping streets eases the way towards civility and tolerance as normal conditions of urban public life (Kasinitz et al., 2016: 196).
\end{abstract}

Similarly, Hiebert et al. (2015: 15) point out that street markets ,reflect the basic sociocultural and socioeconomic diversty of local areas. They bring together people into a public arena who might otherwise remain apart. Also concerned with questions of integration, Peters and de Haan (2011) examine how interethnic encounters in public spaces and immigrant shops in the Netherlands contribute to a higher degree of acceptance of multiculturalism and ethno-cultural diversity.

We think that positive feelings about and experiences of diversity have a significant impact on peoples‘ attitudes. The views people have are based on reality, not on prejudices, stereotypes or media-induced forms of stigmatization. [...] This positive attitude towards diversity and the consequential daily encounters with diversity in public space may make people potentially more open to developing ties with people who are different from themselves (Peters and de Haan, 2011: 186-187).

While these studies are primarily concerned with encounters between immigrants and natives, other researchers of immigrant entrepreneurs' native clientele highlight the ways consumers buy, use and appropriate ethnic products. Jamal, for example, (1996) examines 
the cultural transformation of natives' tastes resulting from encounters with different forms of foreign food. Taking the case of Pakistani supermarkets and grocery stores, he shows how native British customers use and attribute meaning to 'ethnic' food. Applying the concept of acculturation, Jamal suggests that immigrant shops play a significant role as cultural intermediaries.

In a more critical vein, another branch of research examines various ways of exotic appropriation. Influenced by theories of postcolonial studies, a number of scholars emphasise that the consumption of foreign culture may contribute to the production and reproduction of imaginations of 'foreignness' and 'otherness' (Pang, 2002; Michaelsen, 2003; Alraouf, 2010). On the topic of symbolic urban transformation, Zukin (2008) highlights how such imaginations of 'foreignness' are closely related to the desire for 'authenticity', which is typically expressed by members of the upper middle and upper classes. Their social construction of authenticity plays a crucial role in the positive evaluation of the 'other', which may contribute to processes of urban gentrification. Moreover, in the last few years, immigrant economies have grown to play a key role in the processes of city marketing and city branding (Shaw, 2011; Glick-Schiller and Çağlar, 2013). They are considered to be an important contribution to the ethno-cultural diversity of cities and neighbourhoods. This has been at least partly reflected in recent debates on the 'commodification of ethnicity and ethno-cultural diversity' (Kaltmeier, 2011; Aytar and Rath, 2012; Parzer and Huber, fc.).

These studies have fundamentally contributed to our understanding of the various interdependencies between non-migrant customers and immigrant entrepreneurs. However, little is known about consumption as a social practice, including the customers' routines when entering and moving in a shop, selecting and purchasing products as well as interacting with the staff or other customers. In order to fill this research gap, we conducted qualitative research in immigrant food retail in Vienna.

\section{Methods}

The comprehensive qualitative research (November 2013 until October 2014) comprised 31 interviews and 15 go-alongs with native customers in immigrant grocery stores, participant observation, discovery walks through the city and short ethnographic talks with immigrant entrepreneurs and both native and immigrant customers.

Building the core of our qualitative data, the in-depth interviews (Legard et al., 2000) were based on a semi- structured interview guide which addressed products, shops, interactions in the shop in conjunction with matters of social networks, classifications and identity.

Go-alongs - the second pillar of our data - stems from a phenomenologically inspired branch of ethnography and is usually applied in research on everyday life (Kusenbach, 2003). It combines the advantages of participant observation and interviewing. Participants are accompanied while carrying out their (daily) routines. Therefore, it is possible to observe their 'doings' and ask particular questions regarding their thoughts and emotions at the same time. This method is well-suited for analysing consumption practices as it allows to observe bodily routines during shopping and helps to relate it to the stock of knowledge and interpretations attached to the act of shopping.

In advance of the go-alongs and the interviews, systematic discovery walks through the districts of Vienna were carried out. These walks allowed to examine the distribution of immigrant grocery stores across the city; they also enabled us to get an impression of the varieties of immigrant shops and to achieve the necessary sensitivity for our research field.

Based on our knowledge from this exploratory research, we recruited participants mainly in front of the shops. We aimed to achieve a great variety in geographical location, demographic structure in the surrounding district, processes of gentrification, type of the shop and its ethnic self-catgorisation. Even though we tried to make the sample as diverse as possible, there was an extraordinary share of highly educated persons in the sample. Out of 33 interviewees (two interviews were conducted with couples) 21 had a degree and six an A-level. This over-representation of well-educated customers may indicate a specific characteristic of immigrant grocery stores' clientele, but it may also be due to customers' different willingness to participate in the interview and/ or go-along. Data gathered in this extensive fieldwork (recorded and transcribed interviews, field notices and protocols of observations) were analysed using Charmaz's (2014) Grounded Theory-based procedure of coding. Empirical research was carried out until the point of theoretical saturation was reached (Strauss and Corbin, 1998).

\section{Immigrant grocery stores in Vienna}

Polonia Mix, Smak, Gül, Asia Shop, Aycan, Etsan, NER, Prosi - these are just a few names of Viennese grocery stores which are run by entrepreneurs with a migrant 
background. With their various products and ethnic images, they contribute to the economic, social as well as cultural transformation of urban landscapes.

However, these shops vary considerably not only regarding location, size, number of employees, financial success, marketing strategies and products, but also according to ethnic classification (by the entrepreneurs themselves). Concerning the latter, we distinguish four types of the grocery shops' self-presentation:

1. National classification: most of the shops refer to a certain national state; they declare to be a 'Turkish', 'Polish', 'Bulgarian', 'Russian', 'Indian' or 'Italian' grocery store. Usually they highlight ethnic markers and mainly offer foreign products.

2. Transnational classification: this kind of selfpresentation is found in shops which present themselves as 'Orient', 'Arab', 'Eastern-European' or 'Pan-Asian'.

3. International/multi-ethnic classification: this classification is used by grocery shops which offer products from various countries and regions of the world. This form of classification is typical for supermarkets which call themselves 'exotic supermarket' and cover products from two or more continents.

4. Classification beyond any ethnic markers: mainly entrepreneurs who sell only fruits and vegetables avoid referring to their migrant background, but rather highlight the quality of the products.

However, the majority of entrepreneurs promote their shops and products as 'ethnic' or 'exotic', e.g. when they name the shop 'exotic supermarket' or use slogans such as 'deliciously exotic' and 'finest exotic food'.

The heterogeneity in immigrant food retail can only be understood by considering Austria's history coined by a tradition of vivid migration resulting in Austria being an immigrant country. Austrians' immigrant grocery stores mainly are a result of labour migration starting in the 1960s. Most of the workers who came to Austria were recruited in Turkey and the Former Republic of Yugoslavia. The inflow from these two countries continued until the oil crisis of 1973. In the 1990s, Austria once again recorded an increase in immigration, partly due to the civil war in the Former Republic of Yugoslavia and the fall of the Iron Curtain. In the mid-1990s stricter immigration laws were passed, which reduced immigration. The European Union enlargement between 2004 and 2007 gave rise to an acceleration in immigration. Henceforth, immigrants mainly came from countries of the former Eastern bloc and displaced immigration from Turkey and the Former
Republic of Yugoslavia. Currently, migration flows are strongly influenced by the refugees arriving from the Middle East countries who will have an impact on the future landscape of immigrant businesses in Vienna. Geographically, immigrants are mainly located in the bigger cities: On 1 January 2015, Vienna had 1,797,337 inhabitants 661,142 of which had a migrant background (MA23, 2015a). In 2014, ten most represented nationalities, by country of origin, in Vienna were: Austria (64 per cent), Serbia and Montenegro (five per cent), Turkey (four per cent), Germany (three per cent), Poland (three per cent), Bosnia and Herzegovina (two per cent), Romania (two per cent), Croatia (one percent), Hungary (one per cent) and the Czech Republic (one per cent) (MA23, 2015b). Chinese and Indian populations, which seem considerably visible in terms of shops and restaurants, have a comparably low share of the population in Vienna.

Compared to the native population, immigrants have a higher proportion of self-employed: while only seven percent of the Austrian population in Vienna are selfemployed, eleven per cent of the persons with migrant background are so (Schmatz and Wetzel, 2014:1). With about one third of all immigrant business keepers having a university degree, the formal education level is quite high.

Immigrant grocery stores play a crucial role for immigrant communities as they offer immigrants not only familiar products but also co-ethnic contacts, job opportunities, or - on a more symbolical level - means of constructing identity and the feeling of belonging (Halter, 2000; Wang and Lo, 2007; Kraieski de Assunção, 2012). However, it has been observed that immigrant grocery shops are not limited to immigrants. On the one hand, immigrant entrepreneurs in food retail increasingly try addressing members of the so-called majority community (Ram, 1997; Rusinovic, 2008; Parzer and Czingon, 2013). The scope of these 'breakout strategies' ranges from shops which downplay ethnic markers and any migrant background by imitating native shops and mainly offering staple products, such as milk and bread, to those which highlight their origin as a means of guaranteeing authenticity or offering an 'exotic' atmosphere (Engelen, 2001; Parzer and Czingon, 2013). On the other hand, there is evidence that immigrant grocery shops have become increasingly popular among members of the majority community (Stock, 2013; Yildiz, 2013). This is in line with our observation in the field, namely that many 'Austrians' regularly frequent the pan-ethnic, international, Asian and Turkish shops. Many entrepreneurs told us about the high and increasing number of 'Austrians' among their customers. There is, however, no 'typical' consumer 
as such: the heterogeneity in immigrant food retail corresponds with a highly differentiated customer base, including various shopping routines.

\section{Native consumption in immigrant grocery stores}

Native consumption in immigrant grocery stores varies according to the frequency and regularity of shopping (often or seldom; regularly vs. sporadic), the selection of shop(s) in terms of ethnic classification, products on offer and, most significantly, according to the meanings associated with the act of shopping in an immigrant grocery store. However, we also found similarities in terms of patterns of consumption which refer to the collective dimension of shopping in such stores. In the following, two modes of consumption are explained in more detail, namely shopping for convenience and shopping for exceptionality.

\section{Shopping for convenience: 'There is always a Turkish grocery shop around...'}

Many customers favour immigrant grocery stores because of practical reasons and for convenience. They usually purchase 'non-ethnic' products that are also available in native shops such as milk, butter, bread, fruits or vegetables. However, our interviewees mentioned some advantages in comparison to shopping in native shops such as opening hours, geographic location, prices or personal service.

Many immigrant grocery stores have longer opening hours than the native supermarket chains: 'If I go there on Sunday, these shops are always open, and for me milk, bread, butter or fruits is enough. I don't need more' (IC15). ${ }^{1}$ The geographic location is another aspect often mentioned by convenience-shoppers. Sometimes these shops are favoured because they are just around the corner or on the way to or from work. They enable spontaneous shopping in a sporadic way if the need for some products arises:

'I usually shop in Turkish grocery stores while passing by, when I need this or that. Also when I come home late. Well, sometimes I go there because everything else is closed and I want something sweet, or - I don't know - as I said, it is sporadic' (IC25).

1 'IC' refers to our interviews with customers. We conducted all interviews in German. Quotes were translated into English.
Another aspect refers to the prices: most customers assume that the prices are lower than in non-migrant shops. For others, the personal service provided is also a crucial factor why immigrant shops are preferred to native ones. In immigrant corner shops, there is often personal interaction between the shopkeeper and the customers. This advantage mainly rests on the small shop size, which makes direct interaction easier. Furthermore, the shops are rarely crowded, so it is easier to interact with the shopkeepers. For the same reasons, shopping can be completed quickly.

'Well, at Naschmarkt there are a few Asian shops. And they are smaller and there the shop-keepers care about you. You just say what you wish and you are really served. Because it is not a supermarket. It is more like a small shop; it has the ambience of the small native corner shops' (IC30).

All of the stated characteristics distinguishes immigrant shops from the majority of native supermarket chains and makes them more attractive for some Austrians. Interviewees often compare them to former Austrian corner shops, which were replaced by the supermarkets, and highlight their necessity for the district.

'I think this is very important for a big city that you have your area or quarter in the city, where you get the stuff you need. And you don't need everything all the time. Sometimes you just need a little. Well, I am not convinced by the idea that you need big supermarkets everywhere. I also do not like these supermarkets. For me they are stressful and you wait in the line forever' (IC29).

It is remarkable that neither ethnicity nor other differences, such as language or religion, are highlighted by these customers. This indifference to ethnic markers is also reflected in the observation that mainly 'non-ethnic' products, such as milk, bread, butter or vegetables and fruits, are purchased. Rather than referring to ethnicity, immigrant grocery stores are evaluated and appreciated concerning features such as geographical proximity, longer opening hours and personal interaction. However, even though ethnic classification does not seem to play a major role for choosing immigrant shops, some customers indirectly do refer to the shop owners' ethnic origin, surprisingly not as positively as one would expect from customers in immigrant businesses. We thus use the term 'Nevertheless'-consumers to depict those who shop in immigrant stores even though they negatively evaluate the ethnicity attached to the shop. These customers use immigrant stores although they are run by immigrants, simply because some of the above described advantages 'make up' for the negative classification. 'Nevertheless'consumers use immigrant businesses even though they 
have xenophobic resentments against foreigners and may contribute to maintaining ethnic boundaries. However, they are rather the exception of the typical representatives who have positive or at least indifferent attitudes towards the shopkeepers' migrant background.

\section{Shopping for exceptionality: 'It's like being on holiday...'}

Shopping for exceptionality is the second mode of consumption. In contrast to the convenience-shoppers who buy mainly 'non-ethnic' products, shopping for exceptionality is characterised by the purchase of products which are considered to be foreign. Immigrant businesses are regarded as providers of specialities and the related experience and knowledge. They cover a broad variety of products from spices (e.g. curcuma), foreign fruits or vegetables (e.g. kaki) or sweets (e.g. baklava) to processed foods such as humus or sarma. The diversity of products and the perceived difference to native products are positively highlighted: 'It offers the possibility to buy things you wouldn't get anywhere else' (IC10). Often the quality is perceived as higher than in the normal supermarkets: 'I don't get these things anywhere else. From where should I take them otherwise? For example basmati rice. You can get it everywhere, but not of the same quality' (IC21).

Particularly multi-ethnic supermarkets, which offer products from all over the world, are seen to fulfil these consumption needs best: 'It is gorgeous, it is absolutely gorgeous. Because they cover the full range of products from Asia to Africa. Well, you can't buy these things anywhere else. In some cases you can't even buy them online' (IC28).

Even though many native supermarkets do offer foreign products as well, exceptionality-shoppers prefer purchasing foreign products in immigrant shops. They actively highlight the advantages of buying the products in an immigrant store. Besides higher quality and a bigger assortment, personal consultation plays an especially important role for choosing shops run by immigrants: 'If you need special products, you'll get better information in a Chinese shop then from an employee at Spar ${ }^{2}$ who has no idea about it' (IC27). Information on how to handle products on offer is highly appreciated.

'Especially in the Asian shop. She [the salesperson] is always very kind and explains always that you shouldn't mix the Chinese horseradish, the Wasabi, with the Austrian horseradish. She gives such hints all the time. If something doesn't go together well or if something is difficult to tolerate. Well, if there are no people inside and she is not in stress she always talks to me' (IC27).

2 'Spar' is a large supermarket chain in Austria.
The shopkeepers and their co-ethnic staff are also regarded as important providers of expertise because of their migrant background. Many consumers are convinced that these know best how to handle the products they sell because they share the same (assumed) ethnic belonging. This view makes immigrant businesses especially attractive for exceptionality-shoppers: 'But when you pass by, I would buy these things [ethnic products] from the original [ethnic seller]. It's like I would never buy Austrian products in a Turkish shop' (IC17).

Here we see the clear-cut difference between the convenience-shoppers, who primarily buy 'non-ethnic' products, and the exceptionality-shoppers, who mainly purchase foreign products. This is illustrated well by another customer's attitude towards chickpeas: 'Even though you can buy chickpeas in the normal supermarkets, I would never buy them there. This seems so unauthentic to $m e^{6}$ (IC11). Authenticity is considered to be one of the most important criteria for evaluating the quality of products. This also plays a crucial role regarding the origin of certain products:

'There are things like Garam Masala, an Indian mixture of spices. You can buy it in the Austrian wholefood shop. But I already knew that this is not the best if, for instance, Sonnentor ${ }^{3}$ produces the mixture. It is different to an Indian product even though it is manufactured in a big factory in India. The taste and the smell are totally different' (IC13).

This 'imagined originality' corresponds with the disapproval of what is called 'Europeanization' or 'Austrianization' of foreign products: 'The bottom line is that all the spices are all Europeanised and not like the real spice from Thailand' (IC23). Things are supposed to have the 'original' taste, they should be produced in the region where they are supposed to originate from and they should be prepared in the 'correct' way. Regarding the latter, many customers make a point of preparing the purchased products in the way they believe foreigners would.

These assumptions of how to use products in the 'right' way again refer to a construction of authenticity, and again the shopkeepers' migrant background serves as a valuable source of information.

But besides the wish to buy something original, further meanings are attached to the shopping experience. Immigrant businesses often are experienced as places of anti-industrial, down-to-earth-places, whereas, in contrast, native shops are negatively evaluated because they are experienced as greedy and merely profit-oriented:

3 'Sonnentor' is an Austrian organic food company. 
'Well, if I have to make the choice between buying it here [immigrant shop] or there [native supermarket], then I don't want to support Spar with my consumption. Well, I make the effort to go to another store [immigrant business]. If I can buy the same or something similar at Billa and in an Indian Shop, I definitely wouldn't buy at Billa' (IC23). ${ }^{4}$

Within the mode of shopping for convenience, the 'Nevertheless'-consumers were highlighted as an extreme manifestation because they use immigrant businesses even though they feel offended by foreigners. A special type can also be identified within the group of exceptionalityshoppers, forming the extreme pole of the so-called 'Because'-consumers. They choose immigrant businesses primarily because they are run by immigrants and because of the perceived cultural difference. This 'consumption of alterity' is highly dependent on the constructed 'otherness' encountered in immigrant businesses. Ethnicity, its performance and construction are therefore at the core of this mode of consuming. Consumers deliberately and positively highlight the difference to the Austrian culture in terms of the shop, the staff, the products and other customers. Shopping becomes associated with 'holidays' (IC19) or 'southern flair' (IC4).

The experienced alterity is linked to the foreign products, the foreign language labels of the products or phenotypic characteristics of the shop-owners and their employees. The whole process of shopping is celebrated, and the main purpose shifts from buying products to experiencing something extraordinary. By highlighting ethnic difference as a main driver, 'Because'-shopping strengthens ethnic boundaries rather than diminishing them.

Similar findings can be found in research by Everts who examined immigrant food retail in Stuttgart, Germany. Native consumers seem to be curious about foreign products. However, Everts refuses interpreting this kind of inquisitiveness as form of exoticism. Drawing on interviews with native customers, he concludes that shopping is a form of multi-sensory experience rather than a form of exotic appropriation (Everts, 2008: 122125). This is further supported by his observation that ethnicity and ethnic classification hardly play a role for native consumers (Everts, 2008: 124). While we partly agree with Everts regarding shopping for convenience, we do see a significant role of ethnicity and also exoticism in shopping for exceptionality. Here, ethnic classification is important within everyday consumption practices in immigrant grocery stores and may contribute - even if not intended - to the perpetuation of symbolic boundaries between 'us' and 'them'.

4 'Billa' is a large supermarket chain in Austria.

\section{Conclusion}

Immigrant grocery shops have become increasingly popular among members of the majority population. Drawing on interviews, participant observation and go-alongs with non-migrant Austrians, we examined how natives use these shops. We identified two different modes of shopping: while consuming for convenience is characterised by the purchase of native products, combined with the highlighting of practicability, consuming for exceptionality is related to the attraction of an extraordinary experience based on a perceived 'ethnic flair' of the shops, the entrepreneurs, their staff and the offered 'exotic' products.

Our results are partly in line with the findings within the field of consumption research, but challenge some common assumptions on the effects of immigrant entrepreneurs' native clientele on social cohesion.

Many scholars have emphasised how the consumers' images of foreign countries and regions play a central role in native shopping routines (Jamal, 1996; Halter, 2000). This is also reflected in our data as shopping for exceptionality is heavily based on (positive) ethnic classification. On the one hand, this can be seen as an expression of appreciation and recognition of foreign culture. On the other hand, it may also lead to the intensifying of ethnic classification and the strengthening of symbolic boundaries. This is particularly the case in forms of consumption where the 'alterity' of the offered products, as well as the exotic atmosphere, is highlighted ('Because'-consumers).

By contrast, consumption practices that we called 'shopping for convenience' are often considered as an expression of a decreasing significance of ethnic classification. Many scholars emphasise that shopping in immigrant grocery stores has become an everyday routine (Everts, 2008), or at least something that contributes to improving the majority population's handling of cultural diversity and multiculturalism (Yildiz, 2013; Peters and de Haan, 2011). However, going to the immigrant supermarket does not automatically lead to more tolerance and openness. As we have shown, the 'Nevertheless'-consumers use immigrant shops in spite of the entrepreneurs' migrant background and even have xenophobic resentments. Neckel and Sutterlüty explain this ambivalence by referring to the role of economic criteria in purchase decisions, which may displace prejudices (Neckel and Sutterlüty, 2010: 232). Even if negative classifications do not lead to a direct exclusion on a behavioural level, they remain a socially highly relevant symbolic boundary that is drawn between 'us' and 'them'. 
Future research could reveal the conditions under which shopping in immigrant stores becomes an everyday routine. Furthermore, the role of ethnicity has to be examined in more detail - not only regarding the accounts of customers, but also in the interplay with marketing strategies. Further insights into the issue of immigrant grocery stores and its customers would shed light on the interethnic relation between majority and minorities and may contribute to a better understanding of social cohesion and integration in immigration societies such as Austria.

Acknowledgements: We are grateful to Eva Wimmer for her indispensable assistance in the project work. We also thank Renata Nemrava for proofreading.

Funding: The empirical work for this research was funded by the Anniversary Fund of the Austrian National Bank (No. 14706).

Declaration of conflicting interests: Authors declare that there is no conflict of interest.

\section{References}

Alraouf, A. A. (2010) 'Regenerating urban traditions in Bahrain. Learning from Bab-Al-Bahrain: the authentic fake'. Journal of Tourism and Cultural Change, 8(1-2): 50-68.

Aytar, V. and Rath, J. (2012) (eds.) Selling Ethnic Neighborhoods. The Rise of Neighborhoods as Places of Leisure and Consumption. New York: Routledge.

Bonacich, E. (1973) 'A Theory of Middleman Minorities'. American Sociological Review, 38(4): 583-594.

Campbell, C. (1995) ,Sociology of Consumption‘. In Miller, D. (ed.) Acknowledging Consumption: A Review of New Studies, $\mathrm{pp}$. 96-126. London: Routledge.

Charmaz, K. (2014) Constructing Grounded Theory. A Practical Guide Through Qualitative Analysis. London: Sage.

Dhingra, P. (2012) Life behind the Lobby: Indian American Motel Owners and the American Dream. Stanford: Stanford University Press.

Engelen, E. (2001) “"Breaking in“ and „breaking out“: a Weberian approach to entrepreneurial opportunities'. Journal of Ethnic and Migration Studies, 27: 203-223.

Everts, J. (2008) Konsum und Multikulturalität im Stadtteil. Eine sozialgeografische Analyse migrantengeführter Lebensmittelgeschäfte. Bielefeld: transcript.

Glick Schiller, N. and Çağlar, A. (2013) 'Locating migrant pathways of economic emplacement: Thinking beyond the ethnic lens'. Ethnicities, 13: 494-514.

Halter, M. (2000) Shopping for Identity. The Marketing of Ethnicity. New York: Schocken Books.

Hiebert, D., Rath, J. and Vertovec, S. (2015) 'Urban markets and diversity: towards a research agenda'. Ethnic and Racial Studies, 38(1): 5-21.
Jamal, A. (1996) 'Acculturation: the symbolism of ethnic eating among contemporary British consumers'. British Food Journal, 98(10): 12-26.

Jenkins, R. (1994) 'Rethinking Ethnicity: Identity, Categorization and Power'. Ethnic and Racial Studies, 17: 197-223.

Kaltmeier, O. (2011) (ed.) Selling EthniCity: Urban Cultural Politics in the Americas. Farnham and Burlington: Ashgate.

Kasinitz, P., Zukin, S. and Chen, X. (2016) ,Local Shops, Global Streets'. In Zukin, S., Kasinitz, P. and Chen, X. (eds.) Global Cities, Local Streets. Everyday Diversity from New York to Shanghai, pp. 195-206. New York and London: Routledge.

Kraieski de Assunção, V. (2012) 'Circulating Food and Relationships: the Movement of Food (and Other Things) Between Brazilians in Boston and Brazil'. International Review of Social Research, 2: 65-76.

Kusenbach, M. (2003) 'Street Phenomenology: The Go-Along as Ethnographic Research Tool'. Ethnography, 4: 455-485.

Leicht, R. and Langhauser, M. (2014): Ökonomische Bedeutung und Leistungspotenziale von Migrantenunternehmen in Deutschland. Studie im Auftrag der Abteilung Wirtschafts- und Sozialpolitik, Arbeitskreis Mittelstand und Gesprächskreis Migration und Integration der Friedrich-Ebert-Stiftung, Bonn.

Legard, R., Keegan, J. and Ward, K. (2003): 'In-depth Interviews'. In Ritchie, J. and Lewis, J. (eds.) Qualitative research practice: $a$ guide for social science students and researchers, pp. 138-169. London et al.: Sage.

Lu, S. and Fine, G. A. (1995) 'The Presentation of Ethnic Authenticity: Chinese Food as a Social Accomplishment'. The Sociological Quarterly, 36: 535-553.

MA23 Abteilung Wirtschaft, Arbeit und Statistik (2015a): Wien in Zahlen. Available at: https://www.wien.gv.at/statistik/pdf/ wieninzahlen.pdf (accessed 29.02.2016).

MA23 Abteilung Wirtschaft, Arbeit und Statistik (2015b): Wiener Bevölkerung 2014 nach Herkunft. Available at: https://www. wien.gv.at/menschen/integration/grundlagen/daten.html (accessed 29.02.2016).

Michaelsen, A. (2003) 'Asian Food Porn. Fremdheit, Geschlecht und Visualität in Metaphern der Einverleibung zeitgenössischer Populärkultur. ' In Zentrum für transdisziplinäre Geschlechterstudien der Humboldt-Universität zu Berlin (ZtG) Bulletin Texte 32: 240-259. Available at: https://www.gender.hu-berlin.de/ de/publikationen/gender-bulletins/texte-32/bulletin-texte-32 (accessed 02.12.2015).

Min, P. G. (1996) Caught in the Middle: Korean Communities in New York and Los Angeles. Berkeley: University of California Press.

Neckel, S. and Sutterlüty, F. (2008) 'Negative Klassifikationen und die symbolische Ordnung sozialer Ungleichheit'. In Neckel, S. and Soeffner, H.-G. (eds.) Mittendrin im Abseits. Ethnische Gruppenbeziehungen im lokalen Kontext, pp. 15-25. Wiesbaden: Verlag für Sozialwissenschaft.

Pang. C. L. (2002) 'Business Opportunity of Food Pornography? Chinese Restaurant Ventures in Antwerp'. International Journal of Entreprenurial Behaviour \& Research, 8(1/2): 148-161.

Parzer, M. and Czingon, C. (2013) 'Break-out im türkischen Lebensmittelhandel. Neue Perspektiven auf die soziale Einbettung migrantischer Ökonomien'. Österreichische Zeitschrift für Soziologie, 38(1): 55-75.

Parzer, M. and Huber, F.J. (2015), Migrant Businesses and the Symbolic Transformation of Urban Neighborhoods‘. 
International Journal of Urban and Regional Research, 39: 1270-1278.

Peters, K. and de Haan, H. (2011) 'Everyday spaces of inter-ethnic interaction: the meaning of urban public spaces in the Netherlands'. Leisure/Loisir, 35(2): 169-190.

Ram, M. (1997) 'Ethnic minority enterprise: an overview and research agenda'. International Jounal of Entreprenurial Behaviour \& Research, 3: 149-156.

Rath, J., Eurofound (2011) Promoting ethnic entrepreneurship in European cities. Publications Office of the European Union, Luxembourg.

Rusinovic, K. (2008) 'Moving between markets? Immigrant entrepreneurs in different markets'. International Jounal of Entreprenurial Behaviour \& Research, 14: 440-454.

Stock, M. (2013) Der Geschmack der Gentrifizierung. Arabische Imbisse in Berlin. Bielefeld: transkript.

Strauss, A. and Corbin, J. (1998) Basics of qualitative research: techniques and procedures for developing grounded theory. Thousand Oaks: Sage.

Schmatz, S. and Wetzel, P. (2014) Migrantische Ökonomien in Wien. Wien: AK Wien.
Shaw, S. J. (2011) 'Marketing ethnoscapes as spaces of consumption: “Banglatown-London's Curry Capital”'. Journal of Town \& City Management, 1(4): 381-395.

Waldinger, R., Aldrich, H. and Ward, R. (1990) Ethnic entrepreneurs. Immigrant business in industrial societies. Newbury Park, Calif.: Sage.

Wang, L. and Lo, L. (2007) 'Immigrant grocery-shopping behaviour: ethnic identity versus accessibility'. Environment and Planning, 39: 684-699.

Warde, A. (2005) 'Consumption and the theory of practice'. Journal of Consumer Culture, 5: 131-154.

Wimmer, A. (2013) Ethnic Boundary Making. Institutions, Power, Networks. Oxford et al: Oxford University Press.

Yildiz, E. (2013) Die weltoffene Stadt. Bielefeld: transkript.

Zhou, M. (2007) 'Non-Economic Effects of Ethnic Entrepreneurship' In Dana L.-P. (ed.) Handbook of Research on Ethnic Minority Entrepreneurship: A Co-Evolutionary View on Resource Management, pp. 279-288. Cheltenham, UK and Northampton, USA: Edward Elgar.

Zukin, S. (2008) 'Consuming Authenticity. From outposts of difference to means of exclusion'. Cultural Studies, 22: 724-748. 